\title{
Correction to: The RNA binding protein RBMS3 inhibits the metastasis of breast cancer by regulating Twist 1 expression
}

Lei Zhu ${ }^{1+}$, Pei-Wen $\mathrm{Xi}^{1+}$, Xiao-Xia Li ${ }^{3+}$, Xi Sun ${ }^{1}$, Wen-Bin Zhou ${ }^{1}$, Tian-Song Xia ${ }^{1}$, Liang Shi ${ }^{1}$, Yue Hu ${ }^{1}$, Qiang Ding ${ }^{1 *}$ and Ji-Fu Wei ${ }^{2^{*}}$

\section{Correction to: J Exp Clin Cancer Res (2019) 38:105 https://doi.org/10.1186/s13046-019-1111-5}

In the original publication of this article [1], the molecular weight of RBMS3 was incorrectly noted as $38 \mathrm{KDa}$ within Fig, 1a, Fig. 2a and Fig. 2b. The figures have been updated to list the correct molecular weight of RBMS3 as $41 \mathrm{KDa}$.

The authors sincerely apologize for the inconvenience caused to the readers.

\footnotetext{
Author details

'Jiangsu Breast Disease Center, the First Affiliated Hospital with Nanjing Medical University, 300 Guangzhou Road, Nanjing 210029, China. ${ }^{2}$ Research Division of Clinical Pharmacology, the First Affiliated Hospital with Nanjing Medical University, 300 Guangzhou Road, Nanjing 210029, China.

${ }^{3}$ Department of Critical Care Medicine, The First Affiliated Hospital with

Nanjing Medical University, 300 Guangzhou Road, Nanjing 210029, China.
}

Published online: 27 January 2020

\section{Reference}

1. Zhu L, et al. The RNA binding protein RBMS3 inhibits the metastasis of breast cancer by regulating Twist1 expression. J Exp Clin Cancer Res. 2019, 38:105. https://doi.org/10.1186/s13046-019-1111-5.

\footnotetext{
The original article can be found online at https://doi.org/10.1186/s13046019-1111-5

* Correspondence: dingqiang@njmu.edu.cn; weijfu@hotmail.com

†Lei Zhu, Pei-Wen Xi and Xiao-Xia Li contributed equally to this work.

${ }^{1}$ Jiangsu Breast Disease Center, the First Affiliated Hospital with Nanjing Medical University, 300 Guangzhou Road, Nanjing 210029, China

${ }^{2}$ Research Division of Clinical Pharmacology, the First Affiliated Hospital with Nanjing Medical University, 300 Guangzhou Road, Nanjing 210029, China Full list of author information is available at the end of the article
}

(c) The Author(s). 2020 Open Access This article is distributed under the terms of the Creative Commons Attribution 4.0 International License (http://creativecommons.org/licenses/by/4.0/), which permits unrestricted use, distribution, and reproduction in any medium, provided you give appropriate credit to the original author(s) and the source, provide a link to the Creative Commons license, and indicate if changes were made. The Creative Commons Public Domain Dedication waiver (http://creativecommons.org/publicdomain/zero/1.0/) applies to the data made available in this article, unless otherwise stated. 


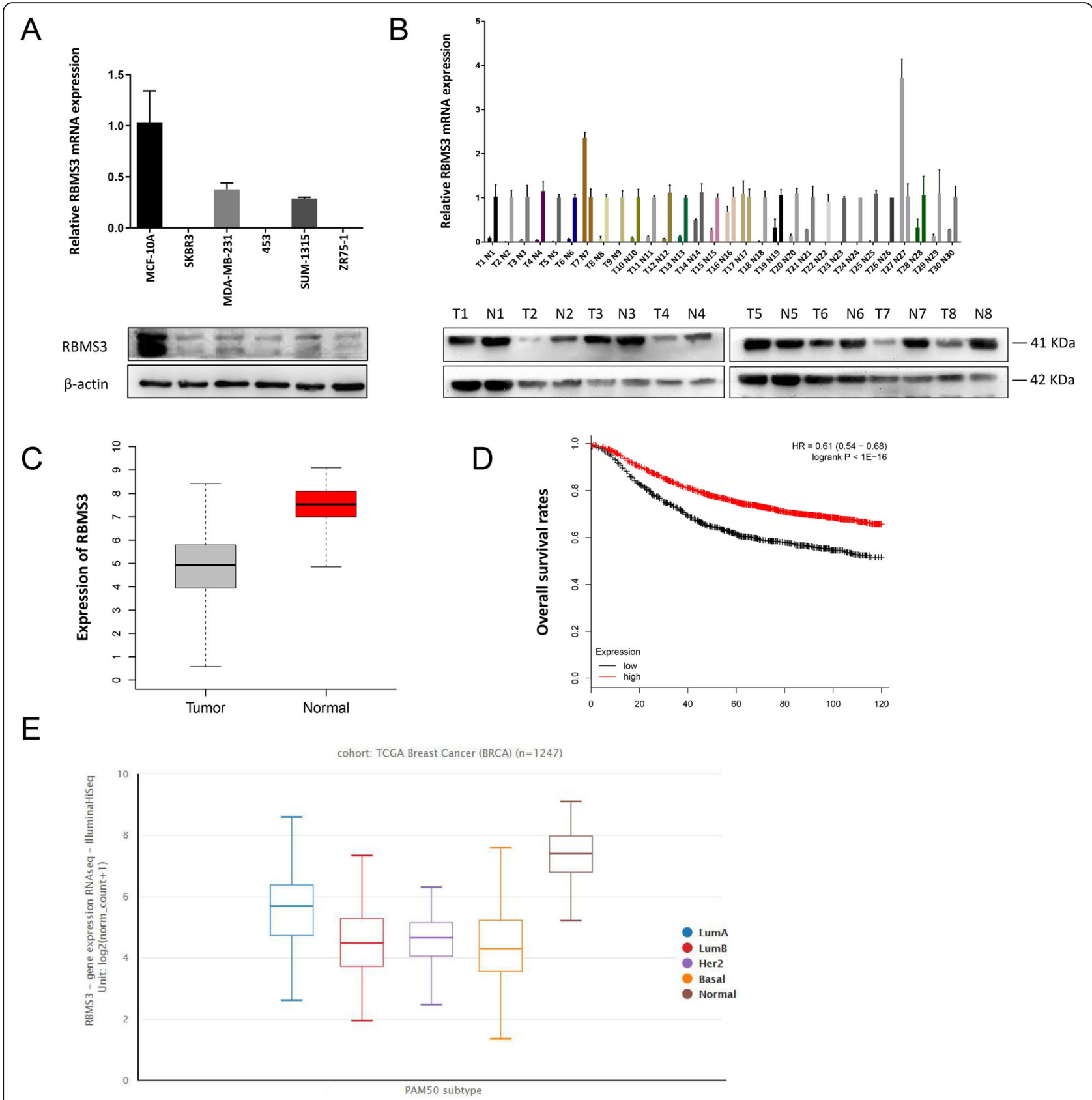

Fig. 1 RBMS3 was downregulated in human breast tumors and correlated with poorer prognosis. a RBMS3 was downregulated in breast cancer cells. The expression levels of RBMS3 in breast cancer cell lines SKBR3, MDA-MB-231, MDA-MB-453, SUM-1315 and ZR75-1 were detected by Western blot and GRT-PCR, and the non-tumorigenic cell line MCF-10A were used as control. b RBMS3 expression was lower in breast cancer tissues. QRT-PCR and western blot were used to detect the expression of RBMS3 in breast cancer tissues and the corresponding adjacent tissues (Reviewer \#1 comment 4). The expression of RBMS3 in breast cancer tissues were normalized to the corresponding adjacent tissues. c Expression of RBMS3 in the TCGA Breast Cancer (BRCA) database, including 1247 samples, $p<0.001$. (Reviewer \#1 comment 2) (d) Kaplan-Meier overall survival curve exhibited patients with breast cancer expressing high (red) levels of RBMS3 had better prognosis than those low (black) levels of RBMS3. Including 3955 samples, $P<0.05$ by log rank test (Reviewer \#1 comment 2). The Affymetrix ID of RBMS3 is 206767_at. (Reviewer \#2 comment 2) (e) RBMS3 was downregulated in the four subtypes of breast cancer compared to normal 


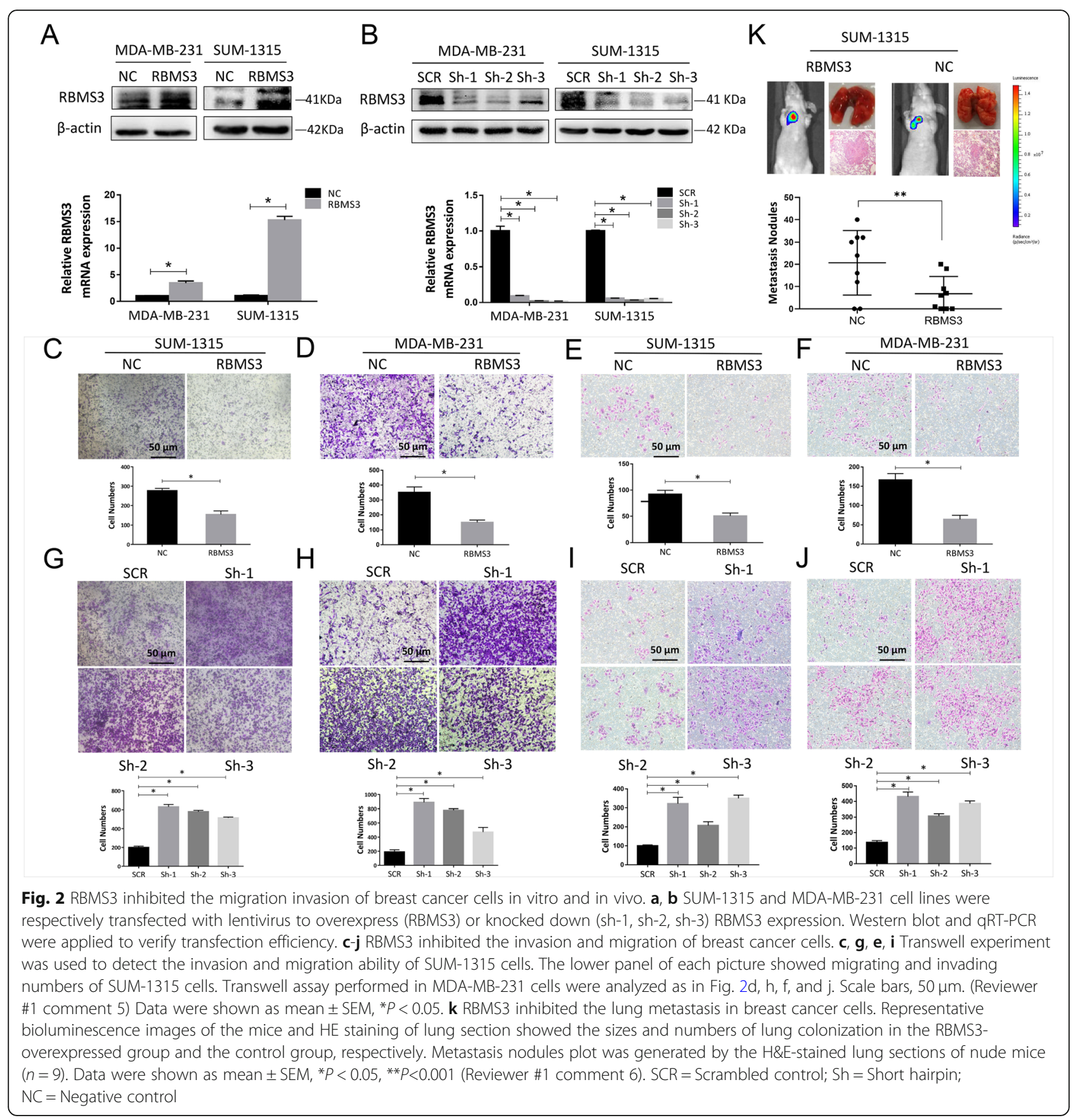

